\title{
Intervention Effects on the Willingness to Stop Smoking and Social Nicotine Dependence Based on Single-Session Group Therapy with Frequent Use of Role Play Targeting Smokers with Mental Disorders
}

\author{
Youhei Komatsu1, Youko Sarada² \\ ${ }^{1}$ Faculty of Rehabilitation Sciences, Nishikyushu University, Kanzaki, Japan \\ ${ }^{2}$ Graduate School of Humanities, Fukuoka University, Fukuoka, Japan \\ Email: komatsuy@nisikyu-u.ac.jp
}

How to cite this paper: Komatsu, Y. and Sarada, Y. (2018) Intervention Effects on the Willingness to Stop Smoking and Social Nicotine Dependence Based on Single-Session Group Therapy with Frequent Use of Role Play Targeting Smokers with Mental Disorders. Open Journal of Medical Psychology, 7, 111-122.

https://doi.org/10.4236/ojmp.2018.74009

Received: August 20, 2018

Accepted: October 19, 2018

Published: October 22, 2018

Copyright (ㅇ 2018 by authors and Scientific Research Publishing Inc. This work is licensed under the Creative Commons Attribution International License (CC BY 4.0).

http://creativecommons.org/licenses/by/4.0/

\begin{abstract}
Objective: We devised a "Smoking-Cessation Motivation Program" as a community welfare service aimed at making short-term improvements in social nicotine dependence and enhancing the willingness to stop smoking among people with mental disorders. Method: The study conducted a controlled trial to empirically examine the effects of the program on the willingness to stop smoking and social nicotine dependence among 26 smokers with mental disorders in the intervention group, who were compared with a control group of 16 individuals. Results: Results demonstrated the program's effectiveness in reducing social nicotine dependence, and a variance analysis with age as the covariate evidenced a mutual interaction between social nicotine dependence and the willingness to stop smoking, confidence to stop smoking, and resisting the temptation to smoke. Conclusion: Future studies should examine longer-term program results, the impact of program duration, and other factors that influence the program's effectiveness.
\end{abstract}

\section{Keywords}

People with Mental Disorders, Smoking-Cessation Intervention, Social Nicotine Dependence

\section{Introduction}

Smoking rate is $2-3$ times higher in people with mental disorders than in the 
general population [1] [2]. People with mental disorders desire smoking-cessation treatments [2]. As a meta-analysis states, "smoking-cessation treatments including the use of group cognitive behavior therapy and smoking-cessation medication are effective against psychiatric disorders as well. But, Effective psychotherapy methods have not been established in meta-analyses" [3] [4] [5]. Schizophrenic patients have language learning disorders [6]. We devise a smoking-cessation motivation program considering these weaknesses and experiential learning to reduce the social nicotine dependence of people with mental disorders using role play to enhance participants' smoking-cessation motivation.

\section{Method}

\subsection{Method of Inviting Participants}

Local residents who wanted to quit smoking were invited to participate in the study through users' meetings and posters in each day care center and employment training office. Those interested were introduced to the researchers.

\subsection{Selection Criteria}

Adults aged 20 or above who live in Japan were targeted. We selected schizophrenic patients interested in quitting smoking who had The Global Assessment of Functioning Scale (hereafter, GAF) [7] of more than 50 points, and had been discharged from a hospital and were living in the community interested in the program at the time of the intervention. A questionnaire was conducted in advance. We selected respondents who stated that they were interested in quitting and scored higher that 0 ("have no intention at all of quitting smoking") on a 10 $\mathrm{cm}$ ("want to quit smoking very much") visual analog scale (VAS). People whose GAF score is higher than 50 has mild to moderate symptoms or no symptoms [7].

\subsection{Exclusion Criteria}

Individuals unable to adapt to group settings were excluded based on judgment from staff and physicians. Those with severe intellectual disabilities and/or exhibiting acute symptoms such as hallucinations, delusions or acute alcohol symptoms were also excluded from the study.

\subsection{Research Design}

After implementing the research participation procedure, control facilities and intervention facilities were allocated randomly through the sealed envelope method. Figure 1 shows the research plan. One program session was conducted at the facility assigned to the intervention group through the allocation process, who completed a pre-survey before the session and a post-survey after the session. A pre-survey was conducted at the facility assigned to the control group, as well as a test to measure exhaled carbon monoxide concentration, and a post-survey was conducted after about an hour of normal activity. 


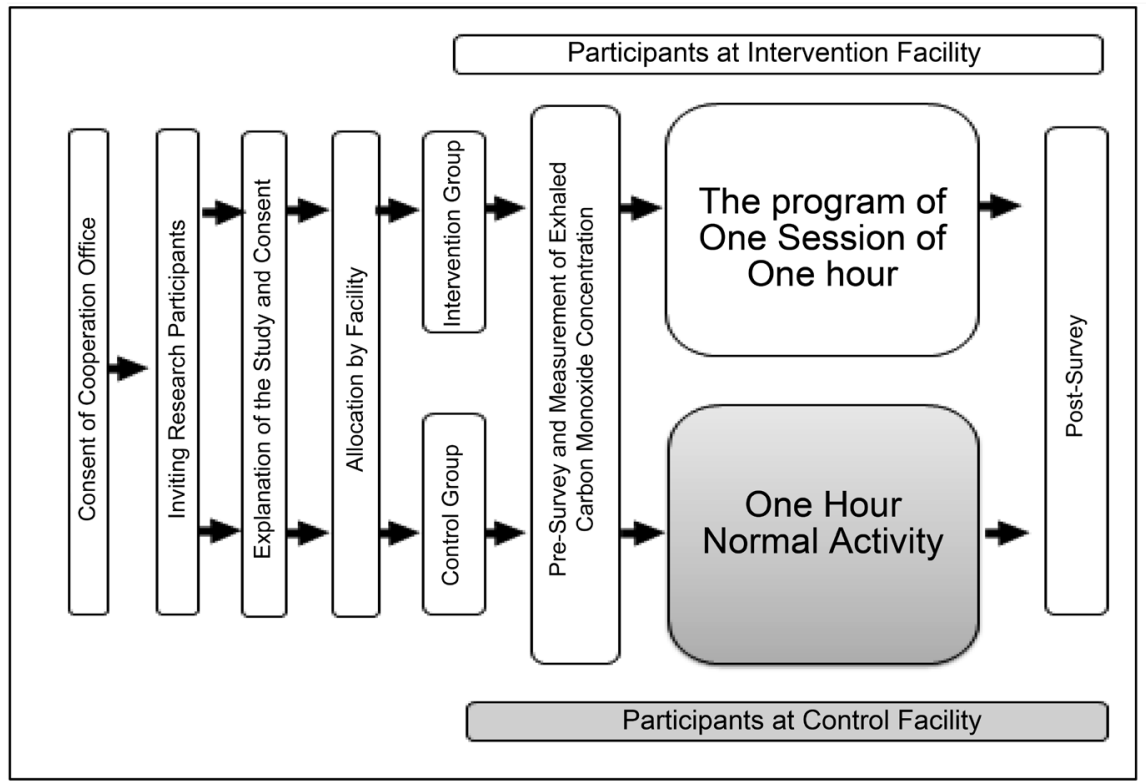

Figure 1. Research flow.

\subsection{Ethical Considerations}

The study was approved by the Ethics Committee of Fukuoka University (authorization number19-6-03), and was implemented after obtaining written, informed consent from the participants

This study was registered as a clinical trial in Japan registry of clinical trials (https://upload.umin.ac.jp) (Register Code: UMIN000033542).

\subsection{Program Overview}

The purpose of the program is to improve the awareness of and motivation for smoking-cessation by communicating useful information for initiating this process for people with mental disorders, by taking into account the learning characteristics of this group. In the self-management module of social skills training, role play has been demonstrated as an effective technique for enhancing drug adherence during the rehabilitation of psychiatric disorders [6], and a similar learning format was adopted for the program.

Further, we included social skills training in line with the US guidelines for short-term smoking-cessation treatment, which include problem solving counseling and skill training as well as social support (encouragement and praise) [8]. Similarly, the same guidelines promote the effectiveness of short-duration (within three minutes) smoking-cessation advice [8]. This content has been narrowed down as much as possible to enable implementation in a small number of sessions over a short-duration.

Detailed content comprises role plays of scenes that involve 1) measuring exhaled carbon monoxide concentration and communicating the results to others; and 2) promoting the acquired merits and benefits of quitting smoking to others.

In addition, our pre-study interview survey, which targeted people with men- 
tal disorders who have been successful in quitting smoking, included an exercise that required participants to imagine themselves as having quit smoking or feel the dangers of smoking by imagining themselves becoming sick due to continued smoking. For this purpose, we used role play scenes wherein participants conversed with others about starting smoking-cessation or spoke to them with pride about having successfully quit smoking. Scenes wherein participants who continued smoking had their individual life expectancy calculated by physicians were also performed, along with the roleplay that had participants say to the doctor: "I want to start smoking cessation treatment".

Further, advice on creating the program was obtained from psychiatrists, physicians, occupational therapists who specialized in rehabilitation of people with mental disorders, health psychologists, clinical psychologists, and other relevant people.

For the intervention group, a text was used and the program comprising a one hour session was implemented in groups of 5 - 10 people. One member of the research team proceeded jointly with two staff members of the cooperating facility, who had trained with the research team regarding the content and method of the program in advance.

\subsection{Index for Evaluating Effects}

\subsubsection{Major Evaluation Items}

The primary evaluation item was the Kano Test for Social Nicotine Dependence (hereafter, KTSND) [9]. A number of studies have used the KTNSD to measure immediate effects of smoking-cessation and smoking-prevention education on nicotine awareness. "The KTNSD was devised to quantitatively evaluate social nicotine dependence, and consists of ten items of three points for a total of 30 points. A higher score denotes stronger social nicotine dependence. The scores of smokers averaged around 18 points, while those of ex-smokers ranged from 12 to 14 points, and non-smokers averaged approximately 12 points. The KTNSD is considered to be a good reflection of the readiness level for smoking-cessation. As the scores decrease the readiness to quit smoking increases and one approaches smoking-cessation" [9]. We thought the level of social nicotine dependence among people with mental disorders is more severe compared with ordinary people; therefore, we assumed that reducing social nicotine dependence would in turn enhance smoking-cessation motivation.

\subsubsection{Secondary Evaluation Items}

\section{1) Willingness to quit smoking}

The question "please tell us how much you want to quit smoking?" was scored on a $10 \mathrm{~cm}$ VAS scale ranging from 0 ("have absolutely no willingness to quit smoking") to 100 ("willing to immediately quit smoking") and evaluated through a self-administered format.

\section{2) Confidence to quit smoking}

The question "please tell us about how confident you are that you will be able 
to continue refraining from smoking?" was scored on a $10 \mathrm{~cm}$ VAS ranging from 0 ("have absolutely no confidence") to 100 ("full of confidence") and evaluated through a self-administered format.

\section{3) Confidence to deal with the temptation to smoke}

The questions "assuming that you have started smoking-cessation, what are the situations when you think you may end up smoking?" and "please tell us about the extent of your confidence that you will be able to refrain from smoking in such situations?" were each scored on a $10 \mathrm{~cm}$ VAS ranging from 0 to 10 ("have absolutely no confidence") to 100 ("full of confidence") and evaluated through a self-administered format.

\section{4) Stages of behavioral change}

Based on the trans-theoretical model [10], the question "are you interested in quitting smoking?" was scored on a four-point scale: 4: "I am thinking of trying to quit smoking within the coming month"; 3 : "I am thinking of trying to quit smoking within the next six months"; 2 : "I am interested in quitting smoking, but I don't think I will be able to quit smoking within the next six months"; and 1: "Not at all interested in quitting smoking". The items were evaluated in a self-administered format.

\subsubsection{Measures of Participant Attributes}

Questionnaires gathered information concerning participants' gender, current age, and the age they began smoking. In addition, the Fagerström Test for Nicotine Dependence (FTND) scale was used to measure the level of physical nicotine dependence. The FTND is composed of six items, such that a score greater than seven points is considered indicative of strong physical dependence [11]. The study also used the Tobacco Dependence Screener (TDS) to measure psychological nicotine dependence. The TDS consists of ten items, and a score greater than five points is screened as nicotine dependence [12]. All the above questions were read aloud by the staff, and the participants filled out the forms independently.

\subsection{Data Analysis}

An $\chi^{2}$ (Chi-2) test was performed on participant attributes (gender, stage of behavioral change) at the time of the pre-survey to compare the characteristics of the control group with those of the intervention group. Further, an unpaired $\boldsymbol{t}$-test was conducted, assessing age and each evaluation item score (in case of non-normality a Mann-Whitney test).

The intervention effects were analyzed by repeated measures two-way variance analysis, then a co-variance analysis accounting for age was conducted.

The analysis of the intervention effects was based on the intention-to-treat analysis, which emphasizes initial allocation. In other words, if there is a missing value in the scores at the time of the post-survey, then the pre-survey score is assigned as is. However, if the pre-survey score has a missing value, then the post-survey score is also considered to have a missing value.

Indicators of behavior change were divided into three stages: progress, main- 
tenance, and regression, measured before and after the intervention, and $\chi^{2}$ test was performed.

SPSS16 was used for the analysis.

\section{Results}

Cooperation for the research was obtained from 46 persons. However, intellectual disabilities and thought disorders were deemed as too severe in two cases, and two others continued to smoke; therefore, a total of four people were excluded based on the exclusion criteria. The target participants now comprised 42 people, of whom 26 were assigned to the intervention group and 16 to the control group. Two people in the intervention group left the study mid-way, but since post-intervention responses had already been obtained, there were no dropouts (Figure 2).

\subsection{Baseline Data Comparison of the Intervention and Control Groups}

The $\chi^{2}$ test and the t-test in the pre-survey are shown in Table 1. As a result, there was a significant difference for age in the two groups, that is, the intervention group and control group $(t=2.54, \mathrm{P}<0.05)$.

\subsection{Examining the Program's Intervention Effects}

The results of the analysis are shown in Table 2 and Figure 3. In the repeated measures two-way variance analysis, a mutual interaction was observed in KTSND $(\mathrm{F}=6.95, \mathrm{P}<0.05)$ and in the confidence to quit smoking $(\mathrm{F}=9.05, \mathrm{P}<0.01)$.

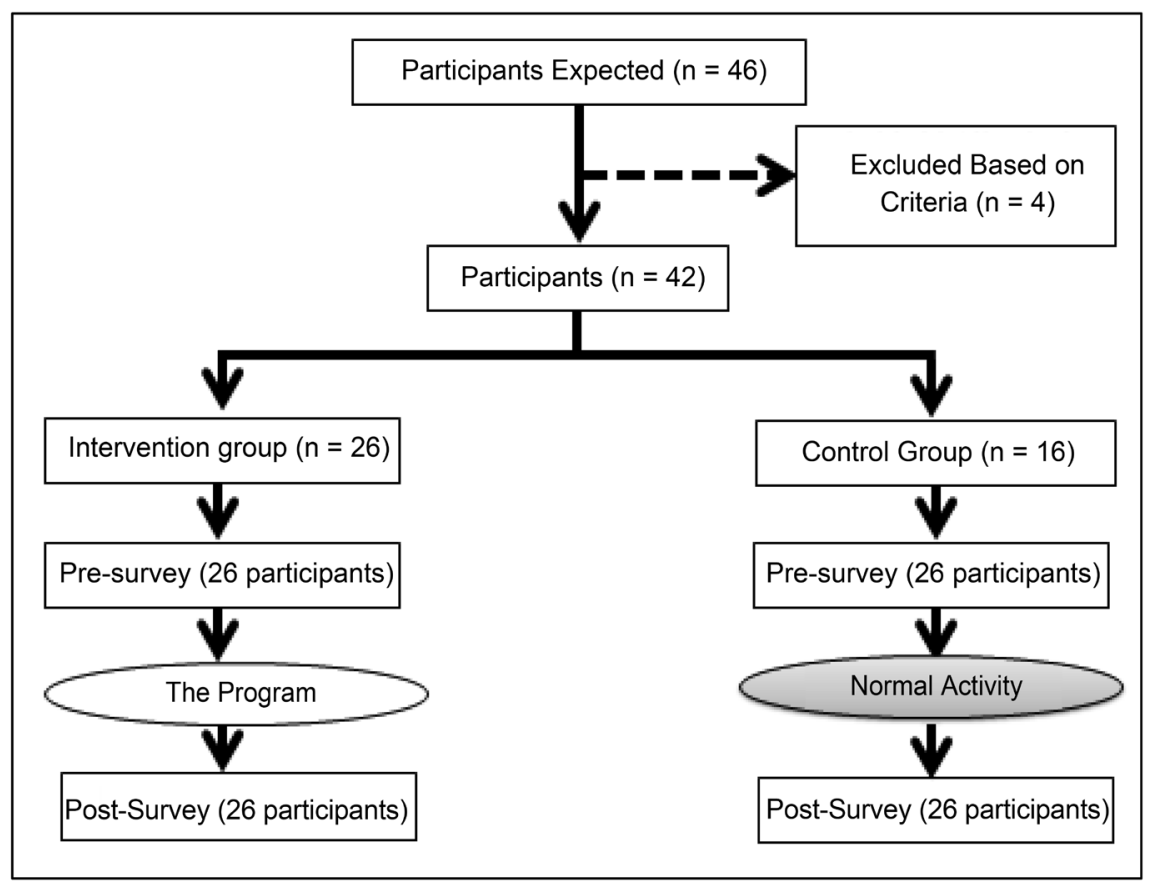

Figure 2. Allocation of participants. 
Table 1. Comparison of intervention group/non-intervention group at pre-survey.

\begin{tabular}{|c|c|c|c|c|c|c|c|}
\hline \multirow{2}{*}{\multicolumn{2}{|c|}{ Variable }} & \multirow{2}{*}{\multicolumn{2}{|c|}{$\begin{array}{l}\text { Intervention group } \\
\qquad(\mathrm{n}=26)\end{array}$}} & \multirow{2}{*}{\multicolumn{2}{|c|}{$\begin{array}{l}\text { Control group } \\
\quad(\mathrm{n}=16)\end{array}$}} & \multirow{2}{*}{\multicolumn{2}{|c|}{$\begin{array}{r}\text { Group comparison } \\
P\end{array}$}} \\
\hline & & & & & & & \\
\hline Age & Average value (standard deviation) & 52.92 & $(11.71)$ & 42.87 & $(13.65)$ & $t=2.54$ & $0.02^{*}$ \\
\hline First time smoking & Average value (standard deviation) & 19.50 & $(5.60)$ & 16.88 & $(5.73)$ & $t=1.46$ & 0.15 \\
\hline Sex Male & Males; n (\%) & 19 & $(73 \%)$ & 11.00 & $(69 \%)$ & \multirow[b]{2}{*}{$\chi^{2}=0.09$} & \multirow[b]{2}{*}{0.76} \\
\hline Female & Females; n (\%) & 7 & $(27 \%)$ & 5.00 & $(45 \%)$ & & \\
\hline FTND & Average value (standard deviation) & 7.12 & $(2.25)$ & 7.13 & $(5.44)$ & $t=-0.01$ & 0.99 \\
\hline TDS & Average value (standard deviation) & 8.00 & $(1.74)$ & 6.56 & $(2.66)$ & $t=1.92$ & 0.07 \\
\hline KTSND & Average value (standard deviation) & 17.08 & $(5.82)$ & 17.94 & $(7.52)$ & $t=-0.42$ & 0.68 \\
\hline Smoking motivation & Average value (standard deviation) & 5.70 & $(3.45)$ & 4.91 & $(3.18)$ & $t=0.75$ & 0.46 \\
\hline $\begin{array}{c}\text { Confidence in being able } \\
\text { to quit }\end{array}$ & Average value (standard deviation) & 2.88 & $(3.00)$ & 3.75 & $(3.01)$ & $\boldsymbol{t}=-0.90$ & 0.38 \\
\hline $\begin{array}{l}\text { Confidence to cope with } \\
\text { smoking temptation }\end{array}$ & Average value (standard deviation) & 3.55 & $(3.87)$ & 2.78 & $(2.30)$ & $t=0.72$ & 0.47 \\
\hline \multirow[t]{3}{*}{ Stage of behavior change } & Immediately; n (\%) & 11 & $(42 \%)$ & 4 & $(25 \%)$ & \multirow{3}{*}{$\chi^{2}=1.46$} & \multirow{3}{*}{0.49} \\
\hline & Within 6 months; n (\%) & 6 & $(23 \%)$ & 4 & $(25 \%)$ & & \\
\hline & Period of concern; $\mathrm{n}(\%)$ & 9 & $(35 \%)$ & 8 & $(50 \%)$ & & \\
\hline
\end{tabular}

*: P $<0.05 ;$ n.s.: significant.

Table 2. Comparison of indicators before and after intervention for each group.

\begin{tabular}{|c|c|c|c|c|c|c|c|c|c|c|c|c|c|c|c|}
\hline & & & & & & \multicolumn{7}{|c|}{$\begin{array}{l}\text { Two-way repeated measures analysis of } \\
\text { variance }\end{array}$} & \multirow{2}{*}{\multicolumn{3}{|c|}{$\begin{array}{c}\begin{array}{c}\text { Analysis of } \\
\text { co-variance for age }\end{array} \\
\text { Reciprocal } \\
\text { action }\end{array}$}} \\
\hline & & \multicolumn{2}{|r|}{ pre } & \multicolumn{2}{|c|}{ post } & \multicolumn{2}{|c|}{$\begin{array}{c}\text { Main effects } \\
\text { (before \& } \\
\text { after) }\end{array}$} & \multicolumn{2}{|c|}{$\begin{array}{l}\text { Main } \\
\text { effects } \\
\text { (group) }\end{array}$} & \multicolumn{3}{|c|}{$\begin{array}{l}\text { Reciprocal } \\
\text { action }\end{array}$} & & & \\
\hline & & $\begin{array}{l}\text { Average } \\
\text { value }\end{array}$ & $\begin{array}{l}\text { Standard } \\
\text { deviation }\end{array}$ & $\begin{array}{l}\text { Average } \\
\text { value }\end{array}$ & $\begin{array}{l}\text { Standard } \\
\text { deviation }\end{array}$ & $F$ & $\mathbf{P}$ & $F$ & $\mathbf{P}$ & $F$ & $\mathbf{P}$ & $\begin{array}{c}\text { partial } \\
\eta^{2}\end{array}$ & $F$ & $\mathbf{P}$ & $\begin{array}{c}\text { partial } \\
\eta^{2}\end{array}$ \\
\hline \multirow{2}{*}{ KTSND } & $\begin{array}{l}\text { Intervention } \\
\text { group }\end{array}$ & 17.08 & 5.82 & 13.81 & 6.06 & \multirow{2}{*}{1.96} & \multirow{2}{*}{0.17} & \multirow{2}{*}{2.31} & \multirow{2}{*}{0.14} & \multirow{2}{*}{6.95} & \multirow{2}{*}{$0.01^{*}$} & \multirow{2}{*}{0.15} & \multirow{2}{*}{0.10} & \multirow{2}{*}{0.75} & \multirow{2}{*}{0.00} \\
\hline & $\begin{array}{l}\text { Control } \\
\text { group }\end{array}$ & 17.94 & 7.52 & 18.94 & 8.12 & & & & & & & & & & \\
\hline \multirow{2}{*}{$\begin{array}{l}\text { Motivation } \\
\text { for smoking }\end{array}$} & $\begin{array}{l}\text { Intervention } \\
\text { group }\end{array}$ & 5.70 & 3.45 & 7.16 & 2.65 & \multirow{2}{*}{6.10} & \multirow{2}{*}{0.02 * } & \multirow{2}{*}{2.09} & \multirow{2}{*}{0.16} & \multirow{2}{*}{2.33} & \multirow{2}{*}{0.18} & \multirow{2}{*}{0.06} & \multirow{2}{*}{4.07} & \multirow{2}{*}{0.05} & \multirow{2}{*}{0.09} \\
\hline & $\begin{array}{l}\text { Control } \\
\text { group }\end{array}$ & 4.91 & 3.18 & 5.25 & 3.44 & & & & & & & & & & \\
\hline \multirow{2}{*}{$\begin{array}{l}\text { Confidence } \\
\text { in quitting } \\
\text { smoking }\end{array}$} & $\begin{array}{l}\text { Intervention } \\
\text { group }\end{array}$ & 2.89 & 3.00 & 4.95 & 2.93 & \multirow[b]{2}{*}{2.59} & \multirow[b]{2}{*}{0.12} & \multirow[b]{2}{*}{0.32} & \multirow[b]{2}{*}{0.57} & \multirow[b]{2}{*}{9.05} & \multirow[b]{2}{*}{$0.01^{*}$} & & & & \\
\hline & $\begin{array}{l}\text { Control } \\
\text { group }\end{array}$ & 3.75 & 3.01 & 3.13 & 3.17 & & & & & & & 0.19 & 4.47 & $0.04^{*}$ & 0.11 \\
\hline $\begin{array}{l}\text { Confidence } \\
\text { to cope with }\end{array}$ & $\begin{array}{l}\text { Intervention } \\
\text { group }\end{array}$ & 3.55 & 3.87 & 4.80 & 2.86 & & & & & & & & & & \\
\hline $\begin{array}{l}\text { smoking } \\
\text { temptation }\end{array}$ & $\begin{array}{l}\text { Control } \\
\text { group }\end{array}$ & 2.77 & 2.78 & 2.06 & 2.44 & 0.27 & 0.60 & 4.43 & 0.04 & 3.63 & 0.00 & 0.09 & 0.94 & 0.33 & 0.03 \\
\hline
\end{tabular}

Intervention group $\mathrm{n}=26$; Control group $\mathrm{n}=16 ;{ }^{*} \mathrm{P}<0.05 ;{ }^{*} \mathrm{P}<0.01$. 
In the co-variance analysis adjusting for the effects of age, mutual interactions were observed in confidence for smoking-cessation $(\mathrm{F}=4.47, \mathrm{P}<0.05)$.

Table 3 illustrates the stages of behavioral change. Both the intervention group and the control group showed high levels of maintenance and no changes (Fisher $=3.28, \mathrm{P}>0.05)$.

\section{Discussion}

We devised a program aimed at improving social nicotine dependence and improvement in the willingness to quit smoking in a short period of time among people with mental disorders with low interest in smoking-cessation. The purpose of this study was to implement a program that targeted people with a psychotic disorder and patients with mental disorders to examine the level of social nicotine dependence and the effects of willingness to quit smoking through a controlled trial.

Table 3. Changes in behavior stages.

\begin{tabular}{ccccc}
\hline & & \multicolumn{3}{c}{ Changes in behavior stages } \\
\cline { 3 - 5 } & & Development & Maintenance & Reversion \\
\hline \multirow{2}{*}{$\begin{array}{c}\text { Intervention } \\
\text { group }\end{array}$} & Exequency & 3 & 21 & 2 \\
& $\%$ & 3.70 & 18.60 & 3.70 \\
Control & Frequency & $11.5 \%$ & $80.8 \%$ & $7.7 \%$ \\
group & Expected frequency & 2.30 & 9 & 4 \\
& $\%$ & $18.8 \%$ & 11.40 & 2.30 \\
\hline
\end{tabular}

Fisher $=3.28, \mathrm{P}>0.05$.

KTSND

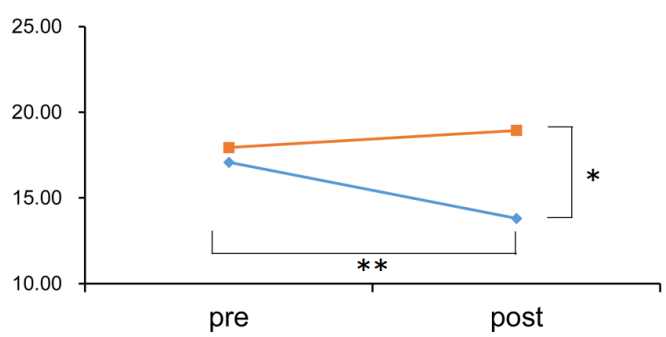

Confidence in quitting smoking

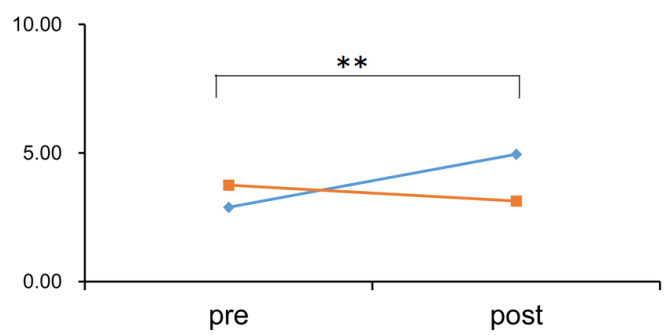

Desire to smoke

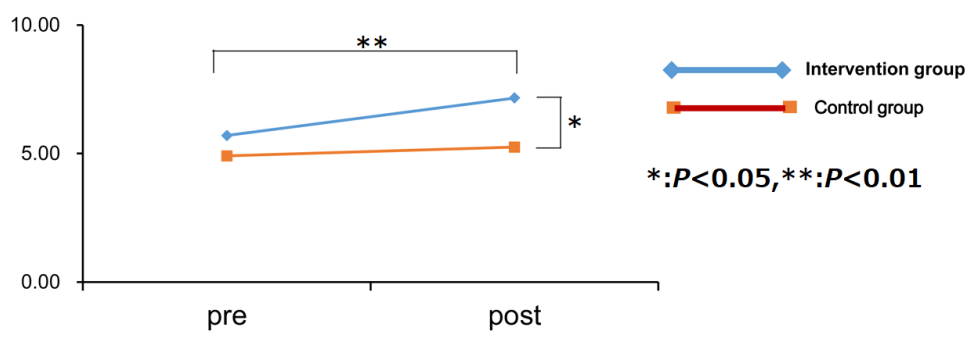

Confidence in coping with smoking temptation

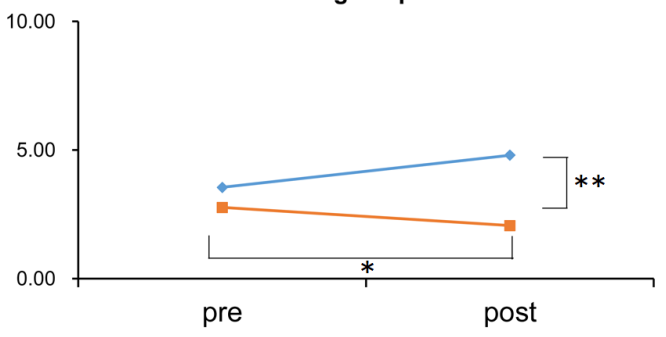

Figure 3. Results of two-way repeated measures analysis of variance according to intervention/non-intervention. 


\subsection{Participant Characteristics}

Most participants received FTND scores greater than seven points, denoting high physical nicotine dependence, and TDS scores for a number of participants significantly exceeded five points considered indicative of nicotine dependence. In addition, the participants had levels of social nicotine dependence consistent with the score of 18 points for ordinary smokers. In other words, participants had a sufficiently high physical nicotine dependence to be considered nicotine dependent. Based on selection criteria, all participants were required to have an interest in smoking-cessation and were people with mental disorders, as well as high social nicotine dependence. As this study included participants who had not been informed of the name of their disorder, we did not examine associations between the intervention and particular illnesses. Therefore, it is unclear which mental disorders were included in the study. Future studies should conduct a detailed examination based on specific disorders.

\subsection{Characteristics of the Intervention Group}

In this study, a random allocation was conducted for each cooperating research facility, but patients at some facilities had a higher average age than those at others. One such facility was assigned to the intervention group with the result being that the average age for the intervention group was significantly higher than that of the control group. There were no significant between-group differences for the other indicators. For this reason, in the analysis of effects, age was taken as a co-variable and the effects of age were analyzed. In addition, there was no statistical difference between the intervention and non-intervention group in terms of smoking-cessation readiness.

\subsection{Effects of Program Intervention}

A repeated measures two-way variance analysis for the intervention effects recognized a mutual interaction for KTSND and the confidence in smoking-cessation. In other words, greater reductions in social nicotine dependence occurred among the intervention group than the control group and the confidence to quit smoking became stronger among the former group. The co-variance analysis considering the effects of age observed mutual interactions in the confidence in smoking-cessation. The confidence in smoking-cessation may be limited age, thus a detailed examination is necessary in future studies.

The results indicated that participating in the program led to reduced levels of social nicotine dependence and the confidence to quit smoking became stronger, which aligns with Prochaska's [13] findings that such interventions can generate an "increase in the awareness to quit smoking" necessary for supporting smoking-cessation even among people with mental disorders. These results indicate the need for reviewing perspectives that emphasize the difficulty of increasing the smoking-cessation motivation of people with mental disorders.

In contrast, many participants in both the intervention group and the control 
group remained at the same stage of behavioral change. Further, this study did not evaluate whether the participants actually began the process of quitting smoking; thus, it is unclear if temporarily participating in the program can improve the level of social nicotine dependence and whether confidence to quit smoking was linked to the start and maintenance of smoking-cessation. Australia's smoking management guidelines for patients with schizophrenia recommend a diagnosis by a smoking-cessation specialist within three days of starting smoking-cessation [14]. Therefore, at the time of "increase in awareness of smoking-cessation" after one program session, it is critical to provide comprehensive smoking-cessation assistance such as individual support and environmental support through early smoking-cessation outpatient visits and assistance, using behavioral therapy which encourages the commencement of smoking-cessation. Further, the program was intended for short-term interventions; therefore, implementation was limited to one session. In the future, it is important to clarify the differences in effects based on the number of sessions.

In addition, this program was implemented by a peer counselor in a similar study [3], and in the future, we would like to train and support peer counselors to implement this program.

\subsection{Limitations and Challenges of This Study}

The challenges and limitations include the following three points. First, since there were a limited number of research facilities complete randomization was not possible. Therefore, the baseline populations showed significant variations in age. In the future, a more rigorous design should be applied for evaluation. Second, this study used a self-administered questionnaire for the effects evaluation index and it does not directly evaluate whether the goal of smoking-cessation commenced and continued. Third, the program could only evaluate psychological effects at the end of the program. Future studies should conduct a multifaceted evaluation of any behavioral and physical changes associated with program participation, as well as clarify changes in behavior and psychological effects over the long term.

Despite the limitations mentioned above, study results indicated that participating in one session of the program could reduce social nicotine dependence, strengthen confidence in the ability to quit smoking, and resist resuming the habit. Future studies should implement a more rigorous research design to 1) examine the objectives and long term effects of the program, including behavioral changes; 2) determine the most effective number of program sessions; 3) and consider the impact of factors such as age, dependence, and willingness to participate on program results.

We devised a "Smoking-Cessation Motivation Program" aimed at reducing social nicotine dependence over the short-term and enhancing the willingness to stop smoking among people with mental disorders living in the local community. The program incorporated the frequent use of role play. The results of a controlled trial examining the effects of social nicotine dependence and the willing- 
ness to quit smoking indicated greater improvements in the level of social nicotine dependence and stronger increase in the confidence to start smoking-cessation among the intervention group as compared with the control group. A co-variance analysis considering the effects of age observed mutual interactions in all the indicators. The effects of the program may be limited based on age with respect to motivation for smoking-cessation and confidence to deal with the temptation to smoke; however, it was seen that participation in a single program session "heightened the willingness to quit smoking". It is important to commence individual smoking-cessation treatments with this timing in mind.

\section{Conflicts of Interest}

The authors declare no conflict of interest. This paper will be submitted to Fukuoka University as part of the doctoral dissertation.

First author Komatsu Youhei designed the study, analyzed the data, and wrote the initial draft of the manuscript. Senior author Sarada Youko contributed to the interpretation of data and assisted in the preparation of the manuscript. All authors have contributed to data collection and interpretation and have critically reviewed the manuscript. All authors have approved the final version of the manuscript and have agreed to be accountable for all aspects of the work and for ensuring that questions related to the accuracy or integrity of any part of the work are appropriately investigated and resolved.

\section{References}

[1] Lasser, K., Boyd, J, Woolhandler, S., Himmelstein, D.U., McCormick, D. and Bor, D.H. (2000) Smoking and Mental Illness: A Population-Based Prevalence Study. JAMA, 284, 2606-2610. https://doi.org/10.1001/jama.284.20.2606

[2] McCreadie, R.G. and Scottish Schizophrenia Lifestyle Group (2003) Diet, Smoking and Cardiovascular Risk in People with Schizophrenia: Descriptive Study. British Journal of Psychiatry, 183, 534-539. https://doi.org/10.1192/bjp.183.6.534

[3] Loreto, A.R., Carvalho, C.F.C., Frallonardo, F.P., Ismael, F., Andrade, A.G. and Castaldelli-Maia, J.M. (2017) Smoking Cessation Treatment for Patients with Mental Disorders Using CBT and Combined Pharmacotherapy. Journal of Dual Diagnosis, 13, 238-246. https://doi.org/10.1080/15504263.2017.1328149

[4] Christiansen, B.A., Carbin, J., TerBeek, E. and Fiore, M.C. (2018) Helping Smokers with Severe Mental Illness Who Do Not Want to Quit. Substance Use \& Misuse, 53, 949-962. https://doi.org/10.1080/10826084.2017.1385635

[5] Baker, A., Richmond, R., Haile, M., Lewin, T.J., Carr, V.J., Taylor, R.L., et al. (2006) A Randomized Controlled Trial of a Smoking Cessation Intervention among People with a Psychotic Disorder. American Journal of Psychiatry, 163, 1934-1942. https://doi.org/10.1176/ajp.2006.163.11.1934

[6] Corrigan, P.W., Liberman, R.P. and Engel, J.D. (1990) From Noncompliance to Collaboration in the Treatment of Schizophrenia. Hospital \& Community Psychiatry, 41, 1203-1211. https://doi.org/10.1176/ps.41.11.1203

[7] American Psychiatric Association (2000) Diagnostic and Statistical Manual of Mental Disorders. 4th Edition, American Psychiatric Association, Washington DC. 
[8] Tobacco Use and Dependence Guideline Panel (2008) Treating Tobacco Use and Dependence: 2008 Update. US Department of Health and Human Services, Rockville.

[9] Yoshii, C., Kano, M., Isomura, T., Kunitomo, F., Aizawa, M., Harada, H., et al. (2006) Innovative Questionnaire Examining Psychological Nicotine Dependence, “The Kano Test for Social Nicotine Dependence (KTSND)". Journal of UOEH, 28, 45-55. https://doi.org/10.7888/juoeh.28.45

[10] Prochaska, J.O. and DiClemente, C.C. (1983) Stages and Processes of Self-Change of Smoking: Toward an Integrative Model of Change. Journal of Consulting and Clinical Psychology, 51, 390-395. https://doi.org/10.1037/0022-006X.51.3.390

[11] Fagerstrom, K. (2012) Determinants of Tobacco Use and Renaming the FTND to the Fagerstrom Test for Cigarette Dependence. Nicotine \& Tobacco Research, 14, 75-78. https://doi.org/10.1093/ntr/ntr137

[12] Kawakami, N., Takatsuka, N., Inaba, S. and Shimizu, H. (1999) Development of a Screening Questionnaire for Tobacco/Nicotine Dependence According to ICD-10, DSM-III-R, and DSM-IV. Addictive Behaviors, 24, 155-166.

https://doi.org/10.1016/S0306-4603(98)00127-0

[13] Prochaska, J.O. and Velicer, W.F. (1997) The Transtheoretical Model of Health Behavior Change. American Journal of Health Promotion, 12, 38-48. https://doi.org/10.4278/0890-1171-12.1.38

[14] Strasser, K., Moeller-Saxone, K., Meadows, G., Hocking, B., Stanton, J. and Kee, P. (2002) Smoking Cessation in Schizophrenia. General Practice Guidelines. Australian Family Physician, 31, 21-24. 